\title{
'Outlines of a world coming into existence': pervasive computing and the ethics of forgetting
}

\author{
Martin Dodge \\ Geography, School of Environment and Development, University of Manchester, Oxford Road, \\ Manchester M13 9PL, England; e-mail: m.dodge@manchester.ac.uk
}

Rob Kitchin

NIRSA and the Department of Geography, National University of Ireland, Maynooth, County Kildare, Ireland; e-mail: rob.kitchin@nuim.ie

Received 18 February 2005; in revised form 26 July 2006; published online 9 March 2007

\begin{abstract}
In this paper we examine the potential of pervasive computing to create widespread sousveillance, which will complement surveillance, through the development of life-logs-sociospatial archives that document every action, every event, every conversation, and every material expression of an individual's life. Reflecting on emerging technologies, life-log projects, and artistic critiques of sousveillance, we explore the potential social, political, and ethical implications of machines that never forget. We suggest, given that life-logs have the potential to convert exterior generated oligopticons to an interior panopticon, that an ethics of forgetting needs to be developed and built into the development of life-logging technologies. Rather than seeing forgetting as a weakness or a fallibility, we argue that it is an emancipatory process that will free pervasive computing from burdensome and pernicious disciplinary effects.
\end{abstract}

\section{Introduction}

"In the course of human (and non human) history, it is rare enough for a significant new regime of recording the past to develop."

Bowker (2003, page 28)

Bowker points to the invention of writing and the printing press as the only two new regimes of recording the past in the last millennium; we posit here that pervasive computing and the concept of life-logs are set to become the third. Pervasive computing, as defined by Galloway (2004, pages 384-385), "seeks to embed computers into our everyday lives in such ways as to render them invisible and allow them to be taken for granted." Pervasive computing aims to augment all aspects of life and activities by seeking to add value through the addition of computing power to everyday objects, rendering them 'smart' to some degree, yet also mundane and routine. A life-log is conceived as a form of pervasive computing consisting of a unified digital record of the totality of an individual's experiences, captured multimodally through digital sensors and stored permanently as a personal multimedia archive. The aim of life-log developers is that they will provide a record of the past that includes every action, every event, every conversation, every material expression of an individual's life; all events will be accessible at a future date because a life-log will be a searchable and recallable archive (see van Dijck, 2005). Such life-logs will constitute new, pervasive, sociospatial archives, because inherent in their construction will be a locational record; it will detail everywhere an individual has been.

Such a conception is fuelled by several factors: firstly, the rollout and adoption of technologies that systematically measure many aspects of social and economic life (eg electronic payment, utility usage, material and information traffic flows, surveillance); secondly, the recognition that digital storage capacity is growing exponentially at the same time, that cost and physical size are falling, and that digital sensors are becoming smaller and more autonomous; and lastly, the fact that there are a number 
of contemporary experiments that seek to integrate captured data within prototype life-logging systems, which are firing developers' imaginations (eg Johnson, 2003; Schofield, 2004). As such, the present ability to capture and store vast amounts of information is inspiring a vision of pervasive computing that generates ubiquitous information of the present, which is kept to become a continuous record of the past. Such information constitutes capta (Dodge and Kitchin, 2005). Capta (derived from the Latin capere, meaning 'to take') are units of data that have been selected and harvested from the sum of all potential data (derived from the Latin dare, meaning 'to give') (Jensen, cited in Becker, 1952). ${ }^{(1)}$ To date, recording regimes have generated capta from an 'exterior' position, generally through one dimension and held by an organisation which is external to an individual and which they do not control (eg, they constitute surveillance). A life-log will generate capta from an interior' (or first-person) perspective, from which the individual watches themselves through intimate technologies (ie, technologies in service to the individual-eg, phones, car, wearable computing), with the capta pooled into a unified, multimedia archive which they control [eg, it constitutes sousveillance-sousveillance being the internal counter to external surveillance (Mann et al, 2003)].

In this paper we examine the potential effects and ethics in a shift from surveillance to sousveillance through the development of pervasive computing, and in particular the notion of life-logging. In the following section we outline existing forms of exterior capta and their uses. We then examine the potential of life-logs to perform sophisticated sociospatial sousveillance and the forms of interior capta it is anticipated they will capture. Section 4 explores the nature of memory within a life-log and raises ethical questions concerning their use and development. In the penultimate section we make the case for an ethics of forgetting and illustrate how such an ethics would be mobilised, before drawing some conclusions. Our analytical perspective is necessarily speculative given the emergent nature of pervasive technologies, but drawing on current empirical materials we follow Thrift's (2004, page 583) recent lead in trying "to capture the outlines of a world just coming into existence, one which is based on continuous calculation at each and every point along each and every line of movement."

Our aim then is to think through possible eventualities and new sociospatial processes and outcomes through the use of the fragmentary discursive and material evidence concerning pervasive computing and life-logging emerging at the time of writing. It is to speculate an imaginative geography of the future that may or may not come to pass; to explore some initial conceptual tools that might be useful in this project; and to start to raise and think through some broader social, political, and ethical questions with respect to pervasive computing, life-logging, and their effects. Our aim is not to detail extensively the mechanics and form of the technical systems being conceived or developed, or which might emerge in the future. Rather, we focus on the implications of such systems and potential countermeasures should they become as widespread as developers hope.

\section{Surveillance: generating exterior capta}

Many everyday activities in public spaces, individual mobilities, and personal interactions are now being routinely and automatically captured and recorded. Such capture is the outcome of processes and practices of surveillance, with the growth in surveillant technologies resulting in a daily deluge of capta that are increasingly being kept, processed, reworked, circulated, and systematically exploited by a range of institutions

(1) Jensen (cited in Becker, 1952, page 278) states that "it is an unfortunate accident of history that the term datum ... rather than captum ... should have come to symbolise the unit-phenomenon in science. For science deals, not with 'that which has been given' by nature to the scientist, but with 'that which has been taken' or selected from nature by the scientist in accordance with his purpose." 
and corporations, ostensibly with the goal of better management of their operations (making them more efficient, more profitable, more secure, safer, and so on). Such surveillance is being directed at all aspects of daily life, including working, consuming, communicating, and recreation, to create a powerful 'capta shadow' (Dodge and Kitchin, 2005; also see Bogard, 1996; Clarke, 1994; Deleuze, 1992; Lyon, 2003).

The workplace, with its unequal power relations, has long been a site where peoples' activities are intensely watched and recorded. The increasing use of software in many working practices has meant that more and more capta on workers are being generated. Such capta are often being used to monitor and to evaluate staff performance and to provide differential rewards and punishments for individual workers (eg Ball, 2003; Marx, 1999). Typical means of capta generation include the use of codes or swipe cards to track employee movement through a workplace and the logging of the use of computer systems (eg keystroke counts) and telephones.

Everyday mobilities are similarly being monitored and recorded into capta shadows. Travellers, on a variety of modes of transport, are rendered identifiable and trackable across their journeys by smartcard ticketing systems (eg the Oyster card on the London Underground), subjected to verification at security screening points, and often observed by blanket CCTV coverage at the terminus and increasingly onboard (eg buses in London). Air travel is the archetypal example, where the possibility for anonymous mobility has been effectively eliminated (see Adey, 2004; Dodge and Kitchin, 2004). However, it is not just mass transportation that is surveyed; roads are increasingly zones of personalised capta generation through the identification and tracking of vehicles. This is enabled through onboard locational devices (eg in-car navigation systems) and also roadside sensor systems (such as London's congestion charging scheme, which tracks all vehicles entering and leaving the centre of the city, through the use of a network of cameras with automatic number-plate-recognition capability). Under pretexts of efficiency and congestion reduction, safety and security, and revenue recovery, it has been hypothesised that in a few years it will not be possible to legally drive without the full journey being registered into a capta shadow (see Dodge and Kitchin, 2005).

Competition, and the drive for ever greater efficiency and profitability, in the provision of retail goods and services by large corporations has also meant ever more capta generated on domestic consumption activities. Shopping patterns are now easily folded into individuals' capta shadows by retailers eager to extract maximum spending from existing customers and to pinpoint likely new 'prospects'. This is facilitated by the identification and tracking of shoppers over time through loyalty cards, frequent customer codes, and electronic payment - to remove, as far as possible, the potential for anonymous purchases. Transactional capta on items purchased, in combination with customer geodemographic typologies based on residence, and lifestyle codes based on sociodemographic characteristics and attitudes, enable the calculation of increasingly sophisticated models of customer's behaviour and, therefore, the prediction of future wants and needs. This knowledge enables retailers to attempt to cater to, and in some senses channel, demand in ways that are most profitable to them. Some of the most sophisticated classification and simulation of customer behaviour is in the provision of financial services, through calculation such as credit scoring (see Leyshon and Thrift, 1999), which has bought benefits to many 'good' consumers [instant credit decisions, cheaper rates, and so on (see McCullagh, 2004)], but which also impacts unequally on 'suboptimal' consumers who pay much more or are automatically determined to be too risky and are excluded. Capta on consumption transactions are also being calculated 'as it happens', as banks watch out for potentially fraudulent events. Here, the detection of fraud is premised on algorithms that watch for transactions 'out of keeping' with a model of a person's 'normal' behaviour determined 
by the capta shadow. Geographic 'normality'-shopping in places that fit your model - is one of the key criteria, along with retailer type, time of day, cost of item, frequency, and sequence of purchases (eg Till and Hand, 2003).

It is not only the raw size and extent of surveillance that have changed in the last few years, but also the emergence of new calculative practices. Capta shadows are increasingly being linked together, processed, 'mined', and analysed in combination, often in real time, with the goal of identifying predictive patterns at the individual level in terms of how people are working, travelling, consuming, communicating, and so on. Capta shadows are being used to make automated judgments about individuals, enacting increasingly sophisticated rankings and classifications along axes of power that meet the needs and agenda of the institution controlling the shadow, rather than the individual (see Graham and Wood, 2003; Lianos and Douglas, 2000). Exterior capta then are the 'fuel' for fine-grained differentiation and social sorting (Lyon, 2003). Such sorting is often not 'felt' directly or is perceived as a benefit (eg faster, easier service from a company; being offered a perk such as discounts or upgrades) and thus welcomed. These automated responses, as Thrift and French (2002) note, produce particular and new sociospatial formations.

That said, many activities and spaces still escape the reach of this regime of recording. As Amin and Thrift (2002, page 128, our emphasis) remind us, "the networks of control that snake their way through cities are necessarily oligoptic, not panoptic: they do not fit together. They will produce various spaces and times, but they cannot fill out the whole space of the city - in part because they cannot reach everywhere, in part because they therefore cannot know all spaces and times, and in part because many new spaces and times remain to be invented." The next question, then, is to what degree will pervasive computing, operating from an 'interior' perspective, produce a very different way of knowing the history of individuals and cities by taking an opposite vantage of viewing: not top-down, but from the inside, looking out?

\section{Sousveillance: generating interior capta through life-logs}

"The MyLifeBits system is designed to store and manage a lifetime's worth of everything - at least everything that can be digitised."

Gemmell et al (2003, original emphasis)

Exterior capta that render people's lives transparent to outside organisations are now partially being complemented by interior capta - the personal documentation of lives as they unfold, an internally self-produced autobiographical sousveillance (see Mann et al, 2003). Here, capta on individual usage are automatically being generated by material objects used on an everyday basis by an individual, such as a phone, a computer, a television, a car, etc (when, where, how long used, but also contentwhat was done, was chosen, was said, etc). In addition, the application of pervasive computing to 'dumb' objects (like fitness equipment, fridges, and other household appliances) seeks to make them 'self aware' to some degree, able to monitor and communicate their usage. These technologies constitute 'history-enriched' digital objects in that they produce autobiographical capta. Moreover, some are supplemented with profiling programmes that adapt the technology to personal preferences (eg, automatic interface customisation, driver settings in the car, predictive texting on mobile phones, etc). These automated forms of sousveillance are being complemented by scopophilic (2) technologies - the conscious self creation and public sharing of sousveillance, for example, through blogging and webcams. 
At present, however, these capta are patchy in nature (in terms of what is actually captured), are not continuously collected (rather, capta are generated only during use), and individual streams of capta are not being amalgamated into a single, unified life-log. Moreover, some present capture technologies are generally still externally controlled and monitored objects and infrastructures-they are third-person technologies (that create biographies) that have first-person potential (to create autobiographies); conceptually the cameras are pointed at the person, rather than pointed by the person.

One of the aims of some pervasive computing enthusiasts is to create a unified, autobiographical (first-person) life-log for each individual through digital technologies that are always on, which communicate with each other without human instruction or intervention, and which are so pervasive that they cover all aspects of human activity and become so banal as to be seemingly invisible - to create a means to personally store all of one's activities throughout a lifetime within a single archive (CARPE, 2004). The prospect is of capturing and storing everything we see and hear- "the totality of information that flows through a human life" (Johnson, 2003, page 85), with the ultimate goal being the simultaneous digitisation of all cognitive 'inputs' experienced by the brain (all five human senses), such that the life-log would be a digital parallel 'memory' of the lived experiences of a person. Much of this just involves taking a separate digital copy for the life-log of all media that the person interacts with (such as songs heard on the radio, e-mail messages, television programmes watched, texts read). This is summarised in figure 1, from one of the leading life-logging projects. The life-log at this point might be seen as a realisation of Bush's (1945) celebrated Memex, "a device in which an individual stores all his books, records, and communications, and which is mechanized so that it may be consulted with exceeding speed and flexibility. It is an enlarged intimate supplement to his memory".

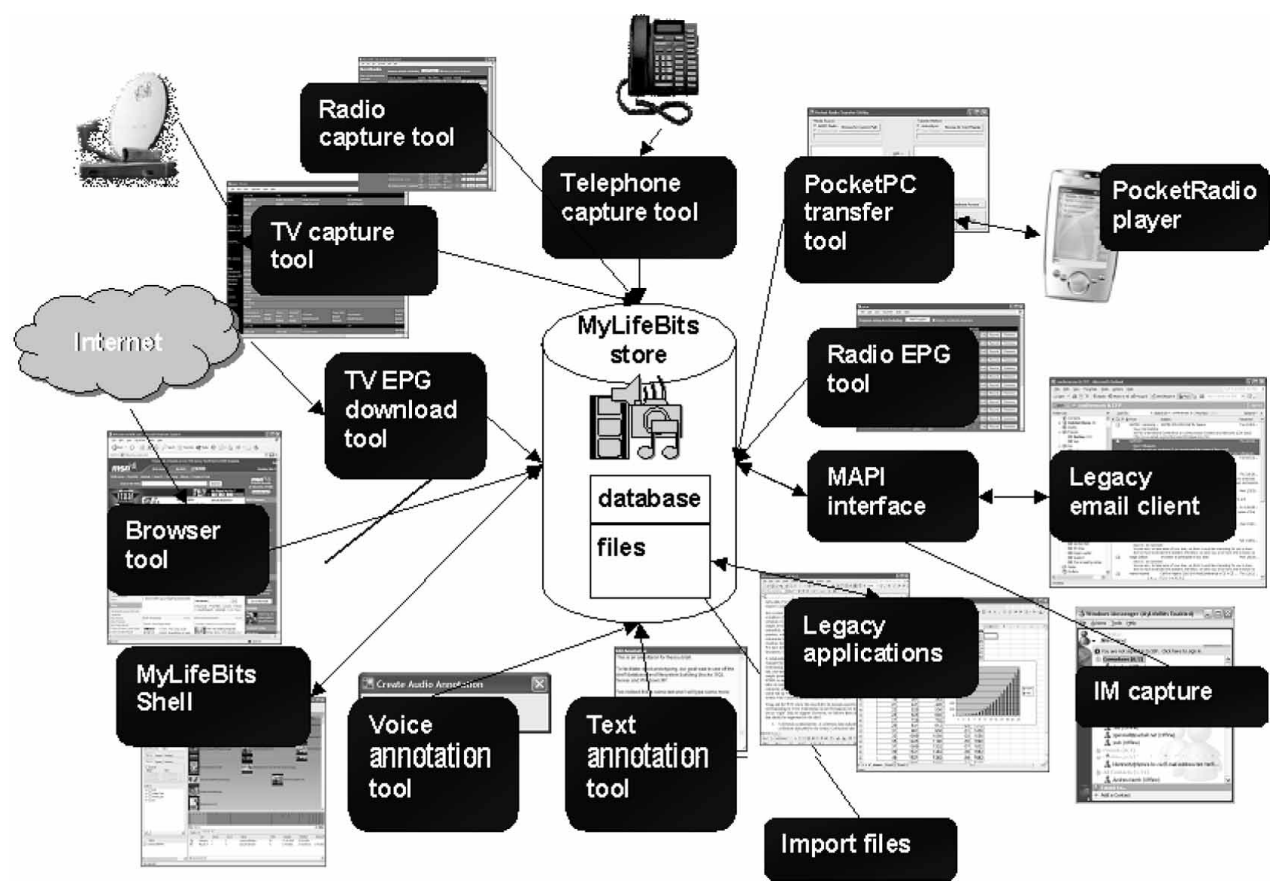

Figure 1. A conceptual model of media capture of the MyLifeBits systems (source: Gemmell et al, 2003). 
In addition, however, life-logs will go beyond Bush's Memex vision because they will be supplemented through wearable computing (including passive continuous voice and visual recording) and complete home-management systems that coordinate all domestic appliances and services (that are themselves interactive, digitally aware, and capable of recording use through software and sensors). These additional capta are likely to be augmented with capta not directly experienced but held unconsciously as biological 'memories', such as physiological conditions inside the body (blood pressure, heart rate, etc) and external conditions (eg orientation, temperature, levels of pollution). A person's life-log, therefore, will not be just an enormous digital archive, it will be "a kind of universal prosthetic memory" which "creates profound differences in our consciousness and in our work practices: all which had been fleeting or consigned to a folder itself consigned to dust is now, should we wish, active and present in our lives" (Bowker, 2003, page 30).

Life-logs will thus provide new means of recording social memories, providing a comprehensive personal archive, intelligently indexed and available on demand for later consultation. Given the range of capta archived, each life-log has the potential to record many significant aspects of daily life from every conversation heard, every person met, every location visited, and every vista viewed. A life-log will therefore be significantly different from personal diaries in that it records, nondiscriminatorily, all personal events; it is an automatically recorded autobiography, captured in a multimedia format, that is always up to date and stored in perpetuity.

Significantly, life-logs will be inherently sociospatial archives because location will be a fundamental capta element of life-logging technologies, automatically built into the sensing systems. This location information will be generated at a fine spatial resolution, pinpointed to (potentially) within a few millimetres through pattern recognition, wireless triangulation to fixed sensor nets, and GPS, and will be dynamically collected so that the precise path of an individual can be recalled. All manner of things will 'know' where they are at all times, while many other 'dumb' objects will be routinely 'chipped' using RFID (radio frequency identification) technologies, making them instantly locatable on demand. Such rich capta will have the effect of opening up new time-space queries that were previously impossible. For example, it will be possible to know every route ever taken, the location of every personal item within a sensor field and the history of that object and its relations to other objects, and to recall every place in which an activity was undertaken. As noted below, there will also be the potential effect of creating a mobile panopticon (as opposed to a partial oligopticon).

The rationale for life-logging centres on the notion of change in the concept of computing. Rather than the concept of a computer for life, pervasive computing is premised on the idea of a 'memory for life' (Fitzgibbon and Reiter, 2003). In particular, a life-log will: reduce physical clutter (there will be no need for photo albums, CDs, notepads, books, etc, because all will be stored in the life-log); allow the efficient managing of materialism and enhance domestic and individual productivity (it will be possible to know where all your possessions are and what conditions they are in); enhance productivity and enjoyment of life by allowing the searching for and recalling of events and actions; enhance the management and recollection of frail memories, particularly in an aging population where there might be significant memory loss; and allow the self-monitoring of health conditions, stress levels, diet and fitness, and other aspects of daily life [systematising and significantly deepening bodily performance monitoring regimes common in today's society (see Schuurman, 2004)]. 
Significant progress is presently being made within the computer science community in exploring life-logging. ${ }^{(3)}$ For example, Sunil Vemuri, a researcher at the MIT Media Lab is developing a personalised sound logging system called 'what was I thinking' that archives all of an individual's conversations and provides means to usefully search the verbatim transcripts via visual interfaces. ${ }^{(4)}$ Researchers at Microsoft Research Lab in Cambridge are developing SenseCam, a device which automatically takes photographs of a person's environment in response to changing conditions (such as body motion, light levels, temperature) (Williams and Wood, 2004). The current prototype, "designed to act like a black box for the human body" (Twist, 2004), is a custom-built digital camera worn like a necklace, with an ultra-wide-angle lens that captures a $132^{\circ}$ view in front of the wearer. The results of SenseCam are a timeline of hundreds of photographs that log activities and spaces as they are encountered throughout the day, which can be interrogated alongside the sensor logs (figure 2). This potential is already being turned into a product. For example, Nokia aim to introduce Lifeblog software that promises to intelligently organise all mobile phone photographs and interactions into a browsable timeline. The SenseCam prototype is also being integrated as a capture component of a larger Microsoft Research project called MyLifeBits. This is probably the most comprehensive life-logging project currently underway, with the aim to 'cyberdise a life', by digitising all existing information of a single test subject (researcher, Gordon Bell) and capturing all its future material informational flows (Gemmell et al, 2003).

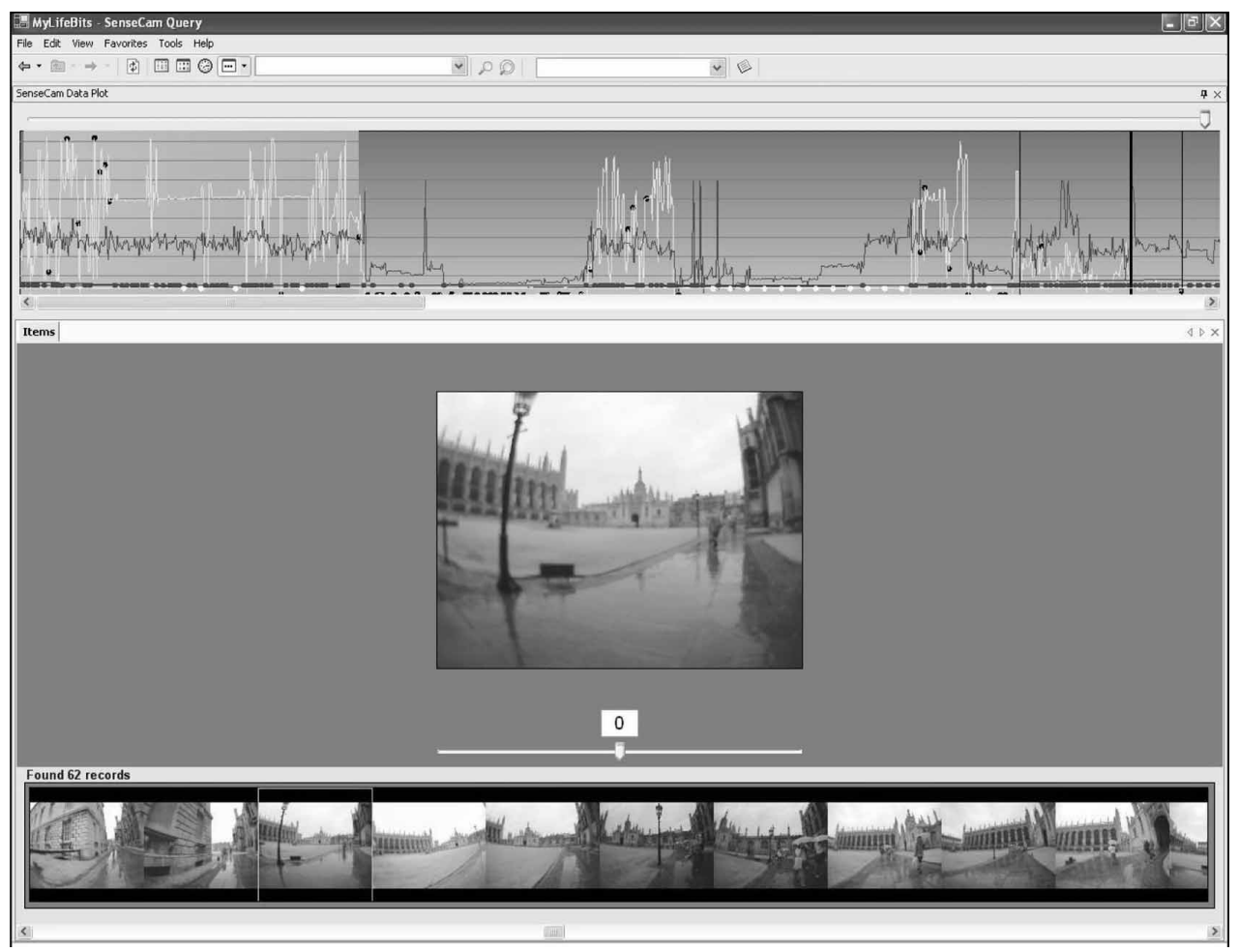

Figure 2. The experimental interface to the photographic log produced by the SenseCam prototype (source: Williams and Wood, 2004).

(3) For otherviews see Nack (2005), van Dijck (2005), and Werkhoven (2004). The proceedings of the CARPE (2004) and Pervasive04 (2004) conferences provide a good sample of research in this area.

(4) See http://www.web.media.mit.edu/ vemuri/wwit/wwit-overview.html. 


\section{Digital memories}

"A record if it is to be useful... must be continuously extended, it must be stored, and above all it must be consulted."

Bush (1945)

"The Western tradition of memory since the Renaissance has been founded upon the assumption that material objects, whether natural or artificial, can act as analogues of human memory."

Forty (1999, page 2, our emphasis)

As Forty details, artefacts have long been recognised as analogues or foils for memory. In the case of archives - such as diaries or photo albums - they record events, people, and places as snapshots in time and space. For people who know the individuals in the archive, context provides emotional connections and further meaning, but for others the archive simply provides a factual account. Here, there is a distinction between what we would call thin memory and thick memory. Thin memory is factual and easily formalised within a media as textual or numeric records, sound, image, etc; it is capta - selected facts captured from the sum of all material data. Thick memory is embedded, emotional, context rich, immaterial - it is remembrances that constitute who a person is and it provides a sense of self. Thick memories are much more than various strands of thin memory tied together, they have emotional and contextual depth that is more than the sum of its parts.

Diaries can provide some resonances of thick memories, but artefacts such as mobile telephones and emerging wearable computing can at best provide only hints, as the material they record and store is largely one dimensional and lacks the interpretation, meaning, and emotive interconnections that a human mind would add. For example, a vista stored within a life-log is simply a view of a place-a collection of $1 \mathrm{~s}$ and $0 \mathrm{~s}$ that constitute a picture. It is a thin memory composed purely of factual information (intensities of colour). It may have some metadata associated with it, but it lacks semantic and emotional meaning. For the person to whom the log relates the picture will prompt thick memories; for others, it, at best, provides only hints of the wider emotional register and personal meaning. Integral meanings are not attached because they were not collected and are not collectable. Life-logs are therefore good for recording thin memory only - the factual details of everyday life, providing a living archive of the minutiae of interactions, transactions, and mobilities.

That said, life-logs clearly have significant implications for the recording of the present, and thus how the past is recalled as opposed to remembered. In terms of what is captured there is a qualitative shift in the granularity (space-time resolution of capta) and fidelity of recording media, and thus the quality of the capta held, and also in complementarities between media which create multidimensional archives (the same events captured by different technologies and subsequently linked together). This is accompanied by a quantitative shift in terms of the volume of personal capta captured, not simply as a function of resolution (a higher resolution picture requires more storage), but in terms of the frequency of capta generated (the number of frames per second, the number of activities recorded, the use of multiple medias, etc) and the mobility of capture (capta are generated from devices carried or worn by the person, not fixed locations such as ATMs and surveillance cameras). In short, capta are becoming continuous across time and space, flowing into the life-log effortlessly as a natural part of the performance of daily life (see Dodge and Kitchin, 2005).

While these technological shifts have the potential to provide rich autobiographical narratives that are of potential use and value to the individual life-logee, allowing the replaying of life events (as superior diaries, interactive photograph albums, and lifeline movies, for example), they raise broader social and political questions. In particular, 
there are questions concerning who owns life-logged capta, how they can be used, and the limits to what is captured.

In relation to ownership, while the capta within a life-log are autobiographical, and will be held by the individual, there are questions concerning access and control. For example, who has rights to access other than the creator? To what extent can the material be sequestered for legal cases and what is the legal status of such material? Do capta take on the same status as biological memories? Or are they seen as more objective and true? What happens when there is a discrepancy between the statements of individuals and the life-log's capta? Are there any other third parties that can have access, such as government security agencies or employers? Would access by third parties (including legal use) be restrictive or nonrestrictive (eg will all capta be available or only selected portions, either by date or media)? Would other people captured by the life-log have claims to access to its contents (such as a partner or friends or work colleagues)? What happens to the life-log at death? ${ }^{(5)}$ Are there inheritance rights and so on? Who has control of a child's life-log? Will life-logs be voluntary or will pressure or mandatory measures by state and capital force people to adopt them?

If life-logs are accessible to third parties, in whatever form, then such access opens up the potential for invasive profiling, social sorting, and pernicious disciplining effects. (The life-log would be in many respects a marketer's dream, enabling them to 'get inside the life' of a consumer to an unprecedented degree.) For example, there is the opportunity to monitor lifestyle, with the life-log providing baseline capta that underpin services such as health and car insurance [as envisaged in Sterling's (1997) novel Holy Fire]. Life-log capta could extend social sorting practices, allowing for preferential treatment of customers and clients that maximises profits, maintains the status quo, and penalises those that fit certain profiles (Gandy, 1993; Lyon, 2003). Moreover, there is the potential for indiscretions, perversions, and minor infractions of the law to be identified and penalised, thus encouraging more rigorous, self-disciplining behaviour, in turn encouraging an ultraconservative society (see also Blanchette and Johnson, 2002). When every action is recorded for perpetuity, in a seemingly objective manner, and there is a likelihood that the consequences will be realised, then Bentham's Panopticon becomes fully realised. This is particularly the case if life-logs are interlinked to create collective profiles.

The vision for life-logs is that they will capture all possible capta, storing it forever. It is not clear, however, to what extent a life-log will be editable, if at all. Should a life-log be editable like a diary or photograph? Should portions be open to selective, permanent erasing? Or just deletion from view, but with the prospect of recovery? Further, should these acts of erasing or deleting themselves be witnessed and remembered by the life-log? Are there events and actions that should be excluded from capture, or at least should there be an option to suspend recording? Can you press pause on the life-log? Would an act of deletion or suspension itself be considered a sign of guilt if the life-log were to be used in law? Do the mundanities of life really need to be captured for perpetuity, such as cleaning the house, walking the dog, or lying on a beach? As Oscar Wilde stated "One should absorb the colour of life, but one should never remember its details. Details are always vulgar" (1988, page 80 ). In addition, to what extent will it be possible to dupe the log, to unsettle the authenticity of the record.

The degradation of biological memory or cognitive disorders are traumatic experiences, as the evidence from forms of dementia and mental illness illustrate. So what

(5) This issue of access and ownership of personal digital records after death is already causing concern, see Selingo (2004). 
would be the impact of accidental or deliberate damage or alteration through the planting of false 'memories' to the life-log? Moreover, could the life-log be stolen and used, perhaps in the same way as stolen passports or identity cards? What would be the consequences for the person whose life-log was stolen, both emotionally and materially?

Some questions about the 'reality' of trying to live in a life-logged world are starting to be thought through and questioned by the work of digital artists. For example, Lucy Kimbell, through her website (http://www.lucykimbell.com) "I measure therefore I am" has undertaken a quantitative personal audit-which includes a stock market style evaluation called $L I X$, "a weekly index that tracked [her] performance between 2002-03 by measuring financial, emotional, social and environmental factors." Multimedia artist Ellie Harrison's projects include Gold Card Adventures, a logging of all her public transport journeys for a year, and the Eat 22 project, where everything she ate for the year after her 22nd birthday was photographed, logged, and displayed online (http:// www.ellieharrison.com). A more generalised questioning of the excesses of consumerist culture was the focus of All-Con\$uming.com (http://www.all-consuming.com), a 'life-logging' type project by artist Stephanie, in which she comprehensively recorded all her purchases in 2001. A total of US \$73549.14 (excluding new home) for 2586 different items and services was spent, all catalogued online with descriptions, photographs, date, time, location, and amount. Lastly, Alberto Frigo's work in 'visual-statistics' questions human's banal dependence on technology through a very exacting type of logging (figure 3). The project is "an ongoing experiment consisting of photographing each time my right hand uses an object in order to create my autobiography for self-reflection and enforcing my identity" (Frigo, 2004, page 52).

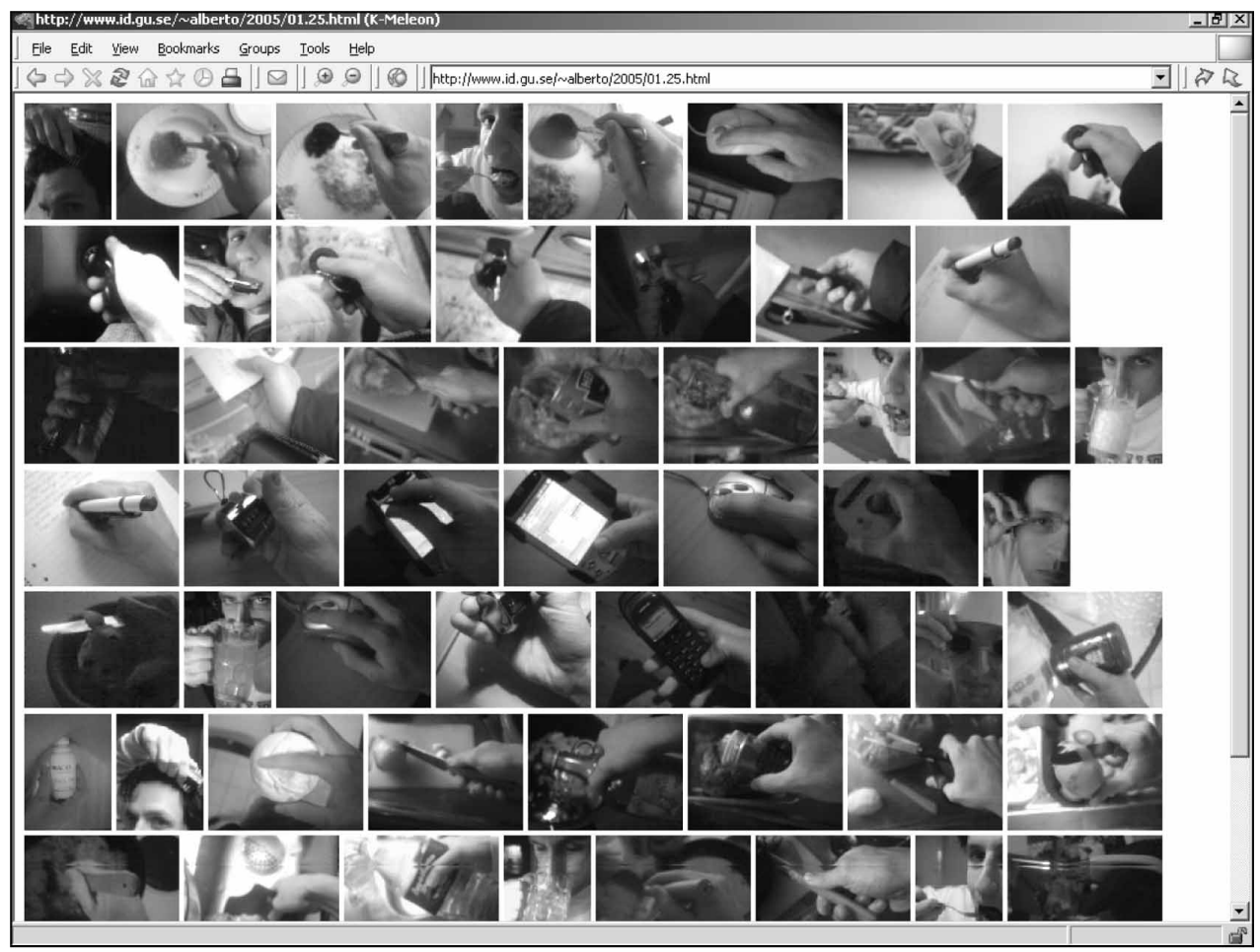

Figure 3. A small part of Alberto Frigo's autobiography project, a manually produced partial 'life-log' of all his interactions with everyday objects (source: http://www.id.gu.se/ alberto/). 


\section{The ethics of forgetting in an age of pervasive computing}

"Much forgetting turns out to be more benefit than bereavement, a mercy rather than malady. To forget is as essential as to keep things in mind, for no individual or collectivity can afford to remember everything."

Lowenthal (1999, page xi)

With respect to the development of sousveillant, life-logging technologies, and the discourses used to support such development, the dilemmas we, and the artist projects described above, raise are strategically avoided by many technologists because they highlight difficult ethical questions concerning events and actions that were previously either private or disparately captured across media and organisations and which were subsequently difficult to stitch together into a coherent, unified whole (see Bannon, 2006). Here we suggest that such dilemmas and questions might be tackled through an ethics of forgetting. In so doing, we want to play devil's advocate to the drive to create technologies that 'store and manage a lifetime's worth of everything' by suggesting that memory should always be complemented by forgetting. We thus posit that forgetting is not a weakness or a fallibility, but is an emancipatory process that will free life-logging from burdensome and pernicious disciplinary effects; as Nietzsche suggests, forgetting will save humans from history (Ramadanovic, 2001).

Human memory is fallible and does not constitute a perfect biological life-log. People forget. Schacter (2001) details six forms of forgetting, three concerned with loss and three with error. ${ }^{(6)}$ Loss-based forgetting consists of transience (the loss of memory over time), absentmindedness (the loss of memory due to distractedness at the time the memory relates to), and blocking (the temporary inability to remember- 'it's on the tip of my tongue'). Error-based forgetting consists of misattribution (assigning a memory to the wrong source), suggestibility (memories that are implanted either by accident or surreptitiously), and bias (the unknowing or unconscious editing or rewriting of experiences). Life-logging aims to overcome both problems of loss and error with respect to thin memories. A life-log will keep a perfect digital record of events and activities that does not decay or fade; technologies will record an exact record; distractedness will be minimised through the cross-referencing of life-log sources; and blocking will be minimised by search and visualisation capabilities. A life-log will minimise errors because the technology will not be open to misattribution, suggestibility, or bias - it will be an exact record of what the sensor 'saw' and will not be open to reinterpretation and reworking. Moreover, the life-log will be augmented through the recording of detail beyond what an individual notices or knows. For example, each 'memory' will be augmented by exact time-space coordinates, and possibly other variables, such as temperature, humidity, and physiological aspects such as heart rate, etc. Moreover, it will add order, precision, completeness, multiple angles (taken from different technologies to provide a multimedia 'memory'), instantaneous recall of the whole archive, searchability, filtering, and analysis (such as cross-referencing, charting of development, producing value-added multimedia recollections, working out spacetime envelopes of activities, and so on) to what human memory or existing memory technologies (such as a photo album) can achieve. In other words, the life-log will not forget, but will augment through added detail. And yet, forgetting is an inherent part of memory.

Perhaps, in the process of designing and implementing life-logging, forgetting should be an integral part of any system. This, we feel should happen from the bottom up and should be a core feature of the life-log, rather than from the top down, wherein

${ }^{(6)}$ Schacter notes one other problem with memory-persistence, the recalling of events that would rather be forgotten. 
legislation or organisational policy is used to regulate 'perfect' life-logs. So, rather than focus on the prescriptive needs for privacy protections, we envisage necessary processes of forgetting, following Schacter's (2001) six forms, that should be built into the system, ensuring a sufficient degree of imperfection, loss, and error. The goal is to make the system humane and yet still useful. For example, in relation to a journey across a city, transience could be achieved by ensuring the fading or loss of details over time, proportional to the length of time lapsed between the generation of the detail and the present. Just as a person would simply start to forget parts of the journey, so the life-log would gradually degrade the precision of the record with time. Absentmindedness could be ensured through distractedness being built into the sensing technologies of capta generation. The log would record the whole journey, but miss out certain pieces of capta, because a recording medium was switched off or was directed at something else. Blocking would be incorporated at the time the life-log was being queried. At other times, the query would be answered with no problems. Misattribution could be achieved by the specific misrecording of part of an event, but not the whole event. For example, part of a journey would be randomly misattributed (eg, having a coffee in Starbucks rather than Caffè Nero), but the overall journey in terms of travelling from A to B would be correct. In other words, misattribution is meaningful in the relations of time, space, and context. It is not the adding of false memories, but rather the 'tweaking' of a past event. Suggestibility would consist of the plausible rescripting of certain events after a particular time. Here, part of the journey would take a subtly different, but believable, route (like taking street A rather than street B). Bias would be achieved by rewriting all events based on pattern recognition; the capta would be rescripted in line with past behaviour, decisions, and preferences to create a record that is consistent and plausible but subtly different. The journey would be an impression of the route rather than a perfect recording, highlighting the things seemingly more important; it would become a 'memory', not a recording. Over time the extent of suggestibility or bias would increase, adding a degree of uncertainty into the capta. Overall, then, a range of algorithmic strategies could be envisioned, such as erasing, blurring, aggregating, injecting noise, data perturbing, masking, and so on, that would be used to 'upset' the life-log records.

\section{Final thoughts}

"But for those first affections,

Those shadowy recollections,

Which, be they what they may,

Are yet the fountain-light of all of our day,

Are yet a master-light of all our seeing."

William Wordsworth

Ode: Intimations of Immortality from Recollections of Early Childhood (1807)

As Bowker (2003) has acknowledged, a new regime of recording the past is starting to come into existence. Life-logging projects presently being developed seek to capture digitally all aspects of daily life as a permanent, archived, replayable record. As such, the multiple exterior surveillant archives which increasingly render peoples' lives transparent to outside organisations will potentially be complemented by widespread interior personal digital documentation of lives as they unfold. In combination, surveillance and sousveillance have the potential capacity to produce a society that never forgets thin memories; that has a permanent sociospatial archive of trillions of events across a vast population, traceable through space and time; a detailed spatialisation of the history of everything, everywhere. Through the recombination of thousands of thin 
memories a factual record of events - the 'master-light of all seeing' — might become a reality.

Such a 'master-light' archive has many potential social, political, and ethical implications with regards to the regulation of everyday life, changing the conditions through which life unfolds. Though it is potentially empowering for individuals, at its logical extreme individuals may come to live in a fully panoptic society with internal sousveillance reflected into external surveillance. Whether such a situation comes to pass only time will tell, but it is important, we believe, to think through the implications of everpresent life-logging as such technologies begin to emerge. To counter the potentially pernicious effects of pervasive computing we have suggested the development of an ethics of forgetting that is materialised through the 'loss of memory' in a life-log. While building fallibility into the system seemingly undermines life-logging, it seems to us the only way to ensure that humans can forget, can rework their past, can achieve a progressive politics based upon debate and negotiation, and can ensure that totalitarian disciplining does not occur. A fallible life-log, underpinned by an ethics of forgetting - an ethics that works at both micro (individual: being able to live with yourself) and macro (collective: being able to live in a society) scales ${ }^{(7)}$-allows humans to be fallible, to evolve their social identities, to live with their conscience, to deal with 'their demons', to move on from their past and build new lives, to reconcile their own paradoxes and contradictions, and to be part of society. Life-logs, as technologists are seemingly conceiving them, are unforgiving of mistakes because of their ubiquitous and merciless memory (Galloway, 2003); forgetting allows forgiving. Without fallibility life-logs might never happen because people will oppose their development. In that sense, forgetting may be an essential ingredient to pervasive computing.

\section{References}

Adey P, 2004, "Surveillance at the airport: surveilling mobility/mobilising surveillance" Environment and Planning A $361365-1380$

Amin A, Thrift N, 2002 Cities: Re-imagining the Urban (Polity Press, Cambridge)

Ball K, 2003, "Categorizing the workers: electronic surveillance and social ordering in the call centers", in Surveillance as Social Sorting: Privacy, Risk and Digital Discrimination Ed. D Lyon (Routledge, London) pp $201-225$

Bannon L, 2006, "Forgetting as a feature, not a bug: the duality of memory and implications for ubiquitous computing" CoDesign 2 3-15

Becker H, 1952, "Science, culture, and society" Philosophy of Science $19273-287$

Blanchette J-F, Johnson D G, 2002, "Data retention and the panoptic society: the social benefits of forgetfulness" The Information Society 1833 -45

Bogard W, 1996 The Simulation of Surveillance: Hypercontrol in Telematic Societies (MIT Press, Cambridge, MA)

Bowker G C, 2003, "The past and the Internet" SSRC Items and Issues $428-30$, http://www.ssrc.org/programs/publications_editors/publications/items/online4-4/bowker-past.pdf

Bush V, 1945, “As we may think” The Atlantic Monthly July 176101 - 108, http://www.theatlantic.com/unbound/flashbks/computer/bushf.htm

CARPE, 2004 First ACM Workshop on Continuous Archival and Retrieval of Personal Experiences 15 October, New York, http://research.microsoft.com/CARPE2004

Clarke R, 1994, "The digital persona and its application to data surveillance" The Information Society $1077-92$

Deleuze G, 1992, "Postscript on the societies of control" October 59 3-7

Dodge M, Kitchin R, 2004, "Flying through code/space: the real virtuality of air travel" Environment and Planning A $36195-211$

Dodge M, Kitchin R, 2005, "Codes of life: identification codes and the machine-readable world" Environment and Planning D: Society and Space 23851 - 881

(7) See also Blanchette and Johnson's (2002) analysis on the importance of institutional forgetfulness to societal well-being. 
Fitzgibbon A, Reiter E, 2003, “'Memories for life': managing information over a human lifetime" UK Computing Research Committee Grand Challenge Proposal 22 May, http://www.nesc.ac.uk/ esi/events/Grand_Challenges/proposals/Memories.pdf

Forty A, 1999, "Introduction”, in The Art of Forgetting Eds A Forty, S Küchler (Berg, Oxford) pp $1-18$

Frigo A, 2004, "Storing, indexing and retrieving my autobiography", in Proceedings of Pervasive 2004 Workshop on Memory and Sharing of Experiences 20 April, Vienna, pp 52 - 56, http://www.ii.ist.i.kyoto-u.ac.jp/ sumi/pervasive04

Galloway A, 2003, "Towards the forgetting machine" Purse Lip Square Jaw weblog, 17 December, http://www.purselipsquarejaw.org/2003_12_01_blogger_archives.php

Galloway A, 2004, "Intimations of everyday life: ubiquitous computing and the city" Cultural Studies $18384-408$

Gandy O H, 1993 The Panoptic Sort: A Political Economy of Personal Information (Westview Press, Boulder, CO)

Gemmell J, Lueder R, Bell G, 2003, "The MyLifeBits Lifetime Store”, in Proceedings of ACM SIGMM 2003 Workshop on Experiential Telepresence (ETP 2003) 7 November, Berkeley, http://www.research.microsoft.com/ JGemmell/pubs/ETP2003.pdf

Graham S, Wood D, 2003, "Digitising surveillance: categorisation, space and inequality" Critical Social Policy $23227-248$

Johnson S, 2003, "Offloading your memories" The New York Times 14 December, page 85, http://www.nytimes.com/2003/12/14/magazine/14OFFLOADING.html

Leyshon A, Thrift N, 1999, "Lists come alive: electronic systems of knowledge and the rise of credit-scoring in retail banking" Economy and Society 28 434-466

Lianos M, Douglas M, 2000, "Dangerization and the end of deviance: the institutional environment" British Journal of Criminology 40261 - 278

Lowenthal D, 1999, "Preface", in The Art of Forgetting Eds A Forty, S Küchler (Berg, Oxford) pp xi-xiii

Lyon D, 2003, "Surveillance as social sorting: computer codes and mobile bodies", in Surveillance as Social Sorting: Privacy, Risk and Digital Discrimination Ed. D Lyon (Routledge, London) pp $13-30$

McCullagh D, 2004, "Database nation: the upside of 'zero privacy'” Reason Magazine 6.04, 26-35, http://www.reason.com/june-2004/mccullagh.pdf

Mann S, Nolan J, Wellman B, 2003, "Sousveillance: inventing and using wearable computing devices for data collection in surveillance environments" Surveillance and Society 1331 - 355

Marx G T, 1999, "Measuring everything that moves: the new surveillance at work", in The Workplace and Deviance Research in the Sociology of Work, volume 8, Eds I Simpson, R Simpson (JAI Press, Greenwich, CT) pp $165-189$

Nack F, 2005, "Lifelogging: capturing every moment of your life" IEEE Multimedia January - March, 4-7

Pervasive04, 2004 Proceedings of Pervasive 2004 Workshop on Memory and Sharing of Experiences 20 April, Vienna, http://www.ii.ist.i.kyoto-u.ac.jp/ sumi/pervasiv04

Ramadanovic P, 2001, "From haunting to trauma: Nietzsche's active forgetting and Blanchot's writing of the disaster" Postmodern Culture 11 http://muse.jhu.edu/journals/pmc/v011/ 11.2ramadanovic.html

Schacter D L, 2001 The Seven Sins of Memory: How the Mind Forgets and Remembers (Houghton Mifflin, Boston, MA)

Schofield J, 2004, "How to save your life" The Guardian 19 August, http://www.guardian.co.uk/ print/0,3858,4995935-110837,00.html

Schuurman N, 2004, "Databases and bodies: a cyborg update" Environment and Planning A 36 $1337-1340$

Selingo J, 2004, "Whose data is it, anyway?" The New York Times 3 June, http://www.nytimes.com/ 2004/06/03/technology/circuits/03data.html

Sterling B, 1997 Holy Fire (Gollancz, London)

Thrift N, 2004, "Movement-space: the changing domain of thinking resulting from the development of new kinds of spatial awareness" Economy and Society $33582-604$

Thrift N, French S, 2002, "The automatic production of space" Transactions of the Institute of British Geographers, New Series 27 309-335

Till R, Hand D, 2003, "Behavioral models of credit card usage" Journal of Applied Statistics 30 $1201-1220$ 
Twist J, 2004, “'Black box'cam for total recall” BBC News Online 15 June, http://www.news.bbc.co.uk/ 1/hi/technology/3797581.stm

van Dijck J, 2005, "From shoebox to performative agent: the computer as personal memory machine" New Media and Society 7311 - 332

Werkhoven P, 2004 Experience Machines: Capturing and Retrieving Personal Content E-content Report 9, ACTeN, August, http://www.acten.net

Wilde O, 1988 The Picture of Dorian Gray (W W Norton, New York), originally published 1891 Ward, Lock \& Co., London

Williams L, Wood K, 2004, "SenseCam: A photographic memory for everyone" Microsoft Research Cambridge Open Day 9 June, http://www.research.microsoft.com/hwsystems/SenseCamOverview/ public.pps

Wordsworth W, 1807 Ode: Intimations of Immortality from Recollections of Early Childhood http://eir.library.utoronto.ca/rpo/display/poem2352.html 
Conditions of use. This article may be downloaded from the E\&P website for personal research by members of subscribing organisations. This PDF may not be placed on any website (or other online distribution system) without permission of the publisher. 